\title{
The association between frailty and severe disease among COVID-19 patients aged over 60 years in China: a prospective cohort study
}

Yao Ma ${ }^{1,2}$, Lisha Hou ${ }^{1}$, Xiufang Yang ${ }^{2,3}$, Zhixin Huang ${ }^{4}$, Xue Yang ${ }^{1}, \mathrm{Na} \mathrm{Zhao}^{5}$, Min He ${ }^{2,6}$, Yixin Shi ${ }^{7}$, Yan Kang ${ }^{2,6^{*}+}$, Jirong Yue ${ }^{1,2^{*}+}$ and Chenkai $\mathrm{Wu}^{8}$

\begin{abstract}
Background: The coronavirus disease 2019 (COVID-19) has been a pandemic worldwide. Old age and underlying illnesses are associated with poor prognosis among COVID-19 patients. However, whether frailty, a common geriatric syndrome of reduced reserve to stressors, is associated with poor prognosis among older COVID-19 patients is unknown. The aim of our study is to investigate the association between frailty and severe disease among COVID-19 patients aged $\geq 60$ years.

Methods: A prospective cohort study of 114 hospitalized older patients ( $\geq 60$ years) with confirmed COVID-19 pneumonia was conducted between 7 February 2020 and 6 April 2020. Epidemiological, demographic, clinical, laboratory, and outcome data on admission were extracted from electronic medical records. All patients were assessed for frailty on admission using the FRAIL scale, in which five components are included: fatigue, resistance, ambulation, illnesses, and loss of weight. The outcome was the development of the severe disease within 60 days. We used the Cox proportional hazards models to identify the unadjusted and adjusted associations between frailty and severe illness. The significant variables in univariable analysis were included in the adjusted model.
\end{abstract}

Results: Of 114 patients, (median age, 67 years; interquartile range $=64-75$ years; 57 [50\%] men), 39 (34.2\%), 39 (34.2\%), and 36 (31.6\%) were non-frail, pre-frail, and frail, respectively. During the 60 days of follow-up, 43 severe diseases occurred including eight deaths. Four of 39 (10.3\%) non-frail patients, 15 of 39 (38.5\%) pre-frail patients, and 24 of $36(66.7 \%)$ frail patients progressed to severe disease. After adjustment of age, sex, body mass index, haemoglobin, white blood count, lymphocyte count, albumin, CD8+ count, D-dimer, and C-reactive protein, frailty $(H R=7.47,95 \% \mathrm{Cl} 1.73-32.34, P=0.007)$ and pre-frailty $(H R=5.01,95 \% \mathrm{Cl} 1.16-21.61, P=0.03)$ were associated with a higher hazard of severe disease than the non-frail.

(Continued on next page)

\footnotetext{
* Correspondence: kangyan@scu.edu.cn; yuejirong11@hotmail.com

${ }^{\dagger}$ Yan Kang and Jirong Yue contributed equally to this work.

${ }^{2}$ COVID-19 Medical Assistance Teams (Hubei) of West China Hospital, Sichuan University, Chengdu, Sichuan Province, China

'Department of Geriatrics and National Clinical Research Center for Geriatrics, West China Hospital, Sichuan University, Chengdu, Sichuan Province, China

Full list of author information is available at the end of the article
}

(c) The Author(s). 2020 Open Access This article is licensed under a Creative Commons Attribution 4.0 International License, which permits use, sharing, adaptation, distribution and reproduction in any medium or format, as long as you give appropriate credit to the original author(s) and the source, provide a link to the Creative Commons licence, and indicate if changes were made. The images or other third party material in this article are included in the article's Creative Commons licence, unless indicated otherwise in a credit line to the material. If material is not included in the article's Creative Commons licence and your intended use is not permitted by statutory regulation or exceeds the permitted use, you will need to obtain permission directly from the copyright holder. To view a copy of this licence, visit http://creativecommons.org/licenses/by/4.0/ The Creative Commons Public Domain Dedication waiver (http://creativecommons.org/publicdomain/zero/1.0/) applies to the data made available in this article, unless otherwise stated in a credit line to the data. 
(Continued from previous page)

Conclusions: Frailty, assessed by the FRAIL scale, was associated with a higher risk of developing severe disease among older COVID-19 patients. Our findings suggested that the use of a clinician friendly assessment of frailty could help in early warning of older patients at high-risk with severe COVID-19 pneumonia.

Keywords: Frailty, COVID-19, Severe disease, Prospective study, Older

\section{Background}

In December 2019, cases of pneumonia with unknown origin pathogen, now known as severe acute respiratory syndrome coronavirus 2 (SARS-CoV-2), emerged in Wuhan, the capital city of Hubei Province in China [1]. The clinical manifestations of this novel disease resembled viral pneumonia [2]. The disease has rapidly spread from Wuhan to other areas in China and the World Health Organization has declared the outbreak of COVID-19 a pandemic on 11 March 2020 [3, 4]. As of 12 May 2020, over 4.0 million of confirmed COVID-19 cases and over 270 thousand deaths have been reported in over 200 countries [5].

Data from China have indicated that old age and underlying illnesses are two strong risk factors for illness and death related to COVID-19 [6-8]. Although the majority of reported COVID-19 cases were mild and the overall case-fatality rate was only $2.3 \%$, over $80 \%$ of deaths occurred among adults aged $\geq 60$ years, and the case-fatality rate increased dramatically from $3.6 \%$ among persons aged $60-69$ years to $14.8 \%$ among those aged $\geq 80$ years [9]. COVID-19 has also posed a disproportionately high threat to older adults in other parts of the world, including the USA and Europe [10,11]. The COVID-19 pandemic has placed an unprecedented burden on health systems and forced health care professionals to make difficult decisions about how to allocate the increasingly scarce resources efficiently $[12,13]$. In some places, decisions are being made about who should be prioritized for medical resources, such as ventilators and ICU beds, based on chronological age $[14,15]$. However, chronological age may not truly reflect the differences underlying the biological ageing process and, therefore, is not an ideal basis for efficient resource allocation and establishing care plans for older COVID-19 patients. Recognizing frailty could help in early warning of older patients at high-risk with severe COVID19 pneumonia.

Frailty is an age-related clinical syndrome of decreased reserve to stressors and is strongly associated with a wide range of adverse outcomes including death, disability, and hospitalization $[16,17]$. Frailty affects over $10 \%$ of older adults in the world and its prevalence is higher at advanced age [18]. The concept of frailty and its assessment has been gradually integrated into clinical practice for evaluating prognosis and establishing goals of treatment [19]. In this sense, provision of frailty screening to older
COVID-19 patients may help identify high-risk group for poor prognosis and formulate patient-tailored treatment goals. Thus, we conducted a prospective cohort study to examine whether frailty status at baseline, assessed by a clinically friendly frailty assessment, would increase the risk of development of severe disease among COVID-19 patients aged $\geq 60$ years.

\section{Methods \\ Study design and participants}

We performed this prospective cohort study across two quarantine floors (wards 23 and 24) in East Campus of Renmin Hospital of Wuhan University, a hospital designated to treat COVID-19 in Wuhan, China. Each floor is equipped with an average of 40 beds. This study was approved by the Ethics Committee of West China Hospital. Because no paper documents are allowed to be taken out of the quarantine area, informed consent was obtained verbally (Y.M) from all participants.

Older patients with confirmed COVID-19 pneumonia admitted to wards 23 and 24 in the East Campus of Renmin Hospital of Wuhan University were screened for enrolment from 7 February 2020 through 6 April 2020. The inclusion criteria were as follows: (1) age $\geq 60$ years, (2) diagnosis of COVID-19 pneumonia according to the WHO interim guidance published on 28 January 2020 [20], (3) completion of frailty assessment on admission (not a proxy), and (4) availability of relevant medical record information. Patients discharged within $24 \mathrm{~h}$ since admission were excluded.

\section{Assessments and outcomes}

At baseline, all participants underwent assessment in 24 $\mathrm{h}$, including socio-demographic data (age, sex, body mass index [BMI]), health behaviours (smoking and drinking), medical history, comorbidities (using the Charlson Comorbidity Index [21]), frailty, and laboratory data (white blood cell count, lymphocyte count, haemoglobin, albumin, creatinine, CD8+, D-dimer, C-reactive protein $[\mathrm{CRP}])$. Subsequently, patients were evaluated daily until hospitalization day 60 or death/discharge via a structured interview for the development of the severe disease. We also contacted patients' relatives by telephone to provide information about the medical history, medications, body weight, and accurate onset time of 
illness when the information could not be directly obtained due to low cognitive function.

Frailty was assessed on admission using the 5-item FRAIL scale, in which five criteria are included: fatigue, resistance, ambulation, illnesses, and loss of weight [22]. Patients met the criterion for fatigue if they responded "All of the time" or "Most of the time" to the question, "How much time during the past four weeks have you felt tired?". Resistance was measured by asking patients if they had any difficulties in walking up ten steps alone without resting and without aids. Ambulation was measured by asking patients if they had any difficulty walking $100 \mathrm{~m}$ alone without aids. Patients met the criterion for illnesses if they reported five or more illnesses out of 11 total illnesses (hypertension, diabetes, cancer [other than a minor skin cancer], chronic lung disease, heart attack, heart failure, angina, asthma, arthritis, stroke, and kidney disease). The loss of weight criterion was met if patients reported a loss of body weight of $5 \%$ or more within the past 12 months. Frailty level was identified by the number of criteria met. Individuals with none were considered "non-frail"; those meeting one or two criteria were considered "pre-frail", and those with three to five criteria were defined as "frail". All participants completed the frailty assessment through self-report by themselves.

The outcome was the development of severe disease within 60 days. According to the WHO Interim guidance for COVID-19 [20], severe diseases of COVID-19 include severe pneumonia, which is defined as fever or suspected respiratory infection, plus one of the following conditions: respiratory rate $>30$ breaths $/ \mathrm{min}$, severe respiratory distress, or $\mathrm{SpO}_{2} \leq 93 \%$ on room air, as well as acute respiratory distress syndrome (ARDS) which is diagnosed according to the Berlin criteria [23]. Participants were censored when they were discharged or the end of the analytic period (60 days), whichever came first discharged.

To minimize error and maximize reliability, the administrator performed the following: (1) providing intensive training to the assessors including frailty and the criteria of severe disease to ensure high inter-rater reliability (kappa $\geq 0.9$ ); and (2) all data were entered and validated by two authors to ensure reliability and accuracy.

\section{Statistical analysis}

We presented the demographic, health behaviours, clinical, and laboratory characteristics by frailty status (nonfrail, pre-frail, and frail) using medians and interquartile ranges (IQR) for continuous variables and counts and percentages for categorical variables. We compared these characteristics according to frailty status using the Kruskal-Wallis test (a nonparametric equivalent of analysis of variance) for continuous variables and chisquared test or Fisher's exact test for categorical variables.

We calculated the incidence rate of severe disease by frailty status. We also used the Kaplan-Meier method to estimate the survival curves of severe disease and used the log-rank (Mantel-Cox) test to compare by frailty status (Fig. 1). Subsequently, we used the Cox proportional hazards models to identify the unadjusted and adjusted associations between frailty and severe illness. The significant variables in univariable analysis were included in the adjusted model. A two-tailed $\alpha$ level of 0.05 was considered statistical significance for all tests. All statistical analyses were performed using SAS 9.4 (SAS Institute Inc., Cary, NC, USA).

\section{Results}

\section{Sample characteristics}

A total of 114 patients were included. The minimum follow-up time was 3 days and the maximum follow-up time was 55 days. The age of the patients ranged from 60 to 96 years and $50 \%$ were men. Thirty-nine (34.2\%), 39 $(34.2 \%)$, and $36(31.6 \%)$ patients were classified as nonfrail, pre-frail, and frail, respectively. There was no significant difference in demographic or clinical characteristics by frailty status. For laboratory characteristics, we found a steep gradient in the median level of white blood cell count, D-dimer, and CRP from non-frail to frail. Frail patients had significantly lower median level of lymphocyte count $(P=0.003)$ and $\mathrm{CD} 8+$ count $(P=0.018)$ than the non-frail and pre-frail (Table 1).

\section{Association between frailty and severe disease}

During the 60 days of follow-up, 43 severe diseases occurred including eight deaths. The results of the univariate analyses were shown in the Additional file. The overall incidence rate of severe disease was 1.48 per 100 person-days (Table 2). The incidence rate of severe disease was $0.32,1.71$, and 3.73 per 100 person-days for non-frail, pre-frail, and frail patients, respectively. As shown in Table 2, 4 of 39 (10.3\%) non-frail patients, 15 of $39(38.5 \%)$ pre-frail patients, and 24 of $36(66.7 \%)$ frail patients progressed to severe disease. The unadjusted hazard ratio of severe disease was 9.98 (95\% confidence internal $[\mathrm{CI}] 3.44-29.00$ ) among frail patients than the non-frail and 4.71 (95\% CI 1.56-14.22) among the prefrail than the non-frail (Additional file 1: Table A1). The association between frailty and severe disease persisted after adjusting for age, sex, BMI, haemoglobin, white blood count, lymphocyte count, albumin, D-Dimer, CRP, and CD8+ count. The HR of severe disease was 7.47 (95\% CI 1.73-32.34) for frail patients than the nonfrail. Pre-frail patients also had a significantly higher hazard of severe disease than the non-frail; the HR was 5.01 


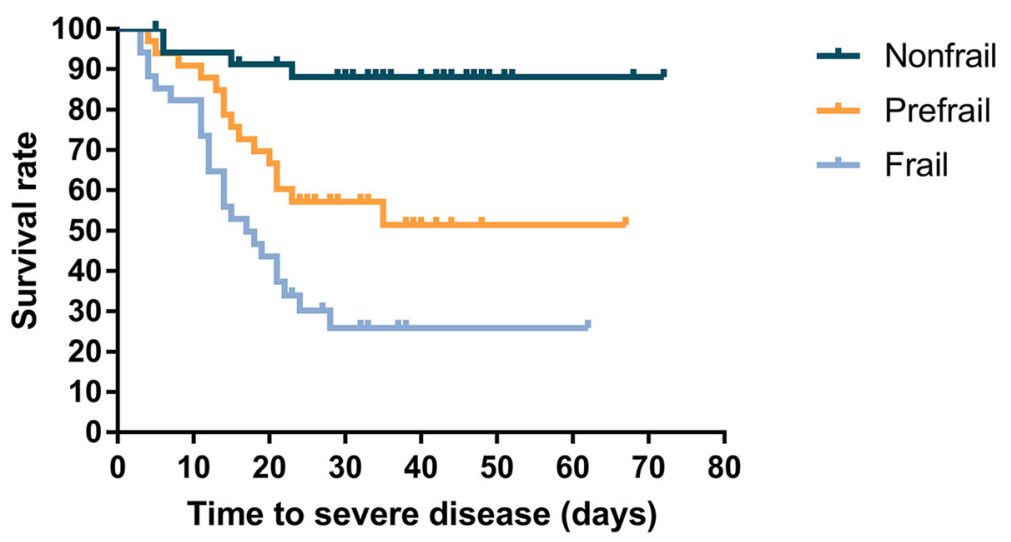

Fig. 1 Kaplan-Meier estimates of the survival rate of severe disease among older COVID-19 patients by frailty status (non-frail, pre-frail, and frail) (non-frail and pre-frail, hazard ratio, 3.549; 95\%Cl, 1.016-12.396; $P=0.047$. non-frail and frail, hazard ratio, 4.963; 95\% Cl, 1.443-17.074; $P=0.011$ )

(95\% CI 1.16-21.61) (Table 3). Kaplan-Meier estimates of the survival rate of severe disease among older COVID-19 patients by frailty status was showen in Fig. 1.

\section{Discussion}

We conducted a prospective cohort study of 114 older COVID-19 patients to examine the association between frailty and severe disease. We found that frailty, assessed by a self-reported frailty screening tool, was an independent risk factor for severe disease among older COVID-19 patients. These findings suggest that the FRAIL scale can be easily applied in a busy clinic setting to identify potentially severe pneumonia patients early and allows us to optimize treatment strategy in advance for older COVID-19 patients.

Since the epidemic of COVID-19, many studies have showed that older age was associated with ARDS after being infected $[6,7,24]$. According to a recent metaanalysis of community-dwelling older adults in Europe, the prevalence of physical frailty is around $15 \%$ for adults aged 65 years and over [25], and it increases to over one quarter among those over 85 years [18]. It would appear that some elderly patients still have a good prognosis, so it seems to be inappropriate to assess the prognosis and make a medical decision simply based on age. Some recent studies suggest that frailty provides better risk stratification for post-operative complications than chronological age [26, 27]. Therefore, it has been suggested that screening of frailty may be suitable for detecting older persons at increased risk of adverse outcomes [28-30]. De Silva et al. reported a positive association between frailty and mortality among nursing home residents [31]. The largest study of frailty in critical illness showed that frail adults were twice as likely to die in the hospital and within 1 year than the non-frail [32, 33]. Frailty is not only independently associated with hospitalizations and mortality in adults with pneumonia but also appears to have a synergistic effect on respiratory function along with lung disease [34, 35] Previous studies have found that age, cardiovascular disease, and cerebrovascular disease were predictive of fatal outcomes [24]. In our study, comorbidities were not associated with higher risk of severe disease in either univariate or multivariate analyses including frailty. These results suggest that frailty may better predict poor prognosis of the older patients with COVID-19 than comorbidities. Thus, we should conduct early frailty assessment, strict medical supervision, and optimal treatment for frail older patients with COVID-19, so as to improve their prognosis. Besides, it is essential to note that there is much potential for frailty to be reversed, particularly in its early stages, such as pre-frailty [36-38]. Therefore, even among the pre-frail or early frail patients with COVID19 , it is possible to improve their prognosis with early and timely management. For this reason, frailty screening should be used to detect old persons with COVID19 for risk stratification and management guidance.

The mechanisms underlying frailty are multiple and reflect the complexity of the ageing process [35]. Theou et al. suggested that every additional year of age was associated with a 3.5 and $2.8 \%$ higher mean frailty index in lower- and higher-income countries, respectively [39]. A low-grade, persistent chronic inflammation, which is socalled inflamm-ageing, is one of the primary reason and pathobiological changes for both ageing and age-related diseases, such as frailty $[35,40]$. Pro-inflammatory cytokines, including IL-6, IL-1, tumour necrosis factor (TNF)-a, C-reactive protein, and fibrinogen levels, may directly accelerate frailty by promoting muscle protein degradation [41], and the pro-inflammatory state may lead to overall suppression of the inflammatory response that is needed to fight an acute respiratory infection [42], including acute virus pneumonia such as COVID- 
Table 1 Baseline characteristics of participants by frailty status

\begin{tabular}{|c|c|c|c|c|}
\hline & Non-frail $(\boldsymbol{n}=39)$ & Pre-frail $(\boldsymbol{n}=39)$ & Frail $(\boldsymbol{n}=36)$ & $\boldsymbol{P}$ value \\
\hline \multicolumn{5}{|l|}{ Characteristics } \\
\hline Age, median (IQR), years & $67(64-74)$ & $68(63-75)$ & $73(66-77)$ & 0.054 \\
\hline Sex, no. (\%) & & & & 0.435 \\
\hline Female & $19(48.72)$ & $17(43.59)$ & $21(58.33)$ & \\
\hline Male & $20(51.28)$ & $22(56.41)$ & $15(41.67)$ & \\
\hline $\mathrm{BMI}, \mathrm{kg} / \mathrm{m}^{2}$ & $23.03(21.2-25.68)$ & $23.04(21.46-25.65)$ & $23.03(22.03-24.99)$ & 0.720 \\
\hline Smoking, no. (\%) & $5(12.82)$ & $8(20.51)$ & $6(16.67)$ & 0.660 \\
\hline Drinking, no. (\%) & $6(15.36)$ & $5(12.82)$ & $6(16.67)$ & 0.892 \\
\hline $\mathrm{CCl}$ & $1(0-2)$ & $1(0-2)$ & $1(0.5-2)$ & 0.420 \\
\hline \multicolumn{5}{|l|}{ Symptoms, no. (\%) } \\
\hline Fever & $32(82.05)$ & $29(74.36)$ & $26(72.22)$ & 0.569 \\
\hline Myalgia & $2(5.13)$ & $6(15.38)$ & $2(5.56)$ & 0.290 \\
\hline Pharyngalgia & $2(5.26)$ & $1(2.56)$ & $1(2.78)$ & 0.843 \\
\hline Dry cough & $28(71.79)$ & $22(56.41)$ & $22(61.11)$ & 0.354 \\
\hline Expectoration & $13(33.33)$ & $14(35.9)$ & $10(27.78)$ & 0.747 \\
\hline Haemoptysis & $4(10.26)$ & $1(2.56)$ & $0(0)$ & 0.126 \\
\hline Dyspnoea & $11(28.21)$ & $16(41.03)$ & $19(52.78)$ & 0.095 \\
\hline Chest pain & $1(2.56)$ & $2(5.13)$ & $1(2.78)$ & 1.000 \\
\hline Anorexia & $20(51.28)$ & $24(61.54)$ & $25(69.44)$ & 0.271 \\
\hline Diarrhoea & $6(15.38)$ & $2(5.13)$ & $4(11.11)$ & 0.327 \\
\hline Nausea & $5(12.82)$ & $3(7.69)$ & $3(8.33)$ & 0.787 \\
\hline Length of stay, median (IQR) & $17(12-30)$ & $25(13-34)$ & $27(12-37)$ & 0.556 \\
\hline Onset-severe time, median (IQR) & $36(29-47)$ & $25(16-38)$ & $16(11-24)$ & $<0.001$ \\
\hline \multicolumn{5}{|l|}{ Laboratory findings, median (IQR) } \\
\hline White blood cell count, $\times 10^{9} / \mathrm{L}$ & $5.44(4.21-6.77)$ & $6.04(4.63-8.03)$ & $6.77(4.53-9.7)$ & 0.024 \\
\hline Lymphocyte count, $\times 10^{9} / \mathrm{L}$ & $1.21(0.79-1.7)$ & $1.07(0.6-1.46)$ & $0.72(0.53-1.21)$ & 0.003 \\
\hline Haemoglobin, g/L & $122(113-132)$ & $118(105-130)$ & $122.5(111-137)$ & 0.581 \\
\hline Albumin, g/L & $37.4(33.2-40.8)$ & $36(32.4-39.6)$ & $36.3(33-37.8)$ & 0.099 \\
\hline \multicolumn{5}{|l|}{ Characteristics } \\
\hline Creatinine, $\mu \mathrm{mol} / \mathrm{L}$ & $65(53-76)$ & $61(53-75)$ & $61.5(47-75)$ & 0.265 \\
\hline 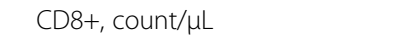 & $236(160-365)$ & $207(120-305)$ & $125(44-329)$ & 0.018 \\
\hline D-dimer, mg/L & $0.8(0.41-1.12)$ & $1.61(0.65-3.93)$ & $1.69(0.67-4.65)$ & 0.004 \\
\hline CRP, mg/L & $5.60(0-63.5)$ & $27.40(0 .-60.20)$ & $55.20(17.80-102.7)$ & 0.008 \\
\hline
\end{tabular}

Data are median (IQR), $\mathrm{n}(\%) . p$ values were calculated by Mann-Whitney $U$ test, $\chi^{2}$ test, or Fisher's exact test, as appropriate $B M I$ body mass index, CRP C-reactive protein

Table 2 Overall incidence rate of severe disease and incidence rate by frailty status

\begin{tabular}{llll}
\hline & Number of severe disease & Total person-days & Events per 100 person-days $(95 \%$ Cl) \\
\hline Total $(n=114)$ & $34(29.82)$ & 2908 & $1.48(1.10-1.99)$ \\
Non-frail $(n=39)$ & $4(10.28)$ & 1265 & $0.32(0.12-0.84)$ \\
Pre-frail $(n=39)$ & $15(38.46)$ & 879 & $1.71(1.03-2.83)$ \\
Frail $(n=36)$ & $24(66.67)$ & 643 & $3.73(2.50-5.57)$ \\
\hline
\end{tabular}


Table 3 Association between frailty and severe disease

\begin{tabular}{|c|c|c|}
\hline \multirow{2}{*}{$\begin{array}{l}\text { Frailty } \\
\text { status }\end{array}$} & Minimal adjusted model* & Adjusted model $\left.\right|^{\#}$ \\
\hline & \multicolumn{2}{|c|}{ Hazard ratio ( $95 \%$ confidence interval) } \\
\hline Non-frail & Ref. & Ref. \\
\hline Pre-frail & $4.86(1.61-14.71)$ & $5.01(1.16-12.61)$ \\
\hline Frail & $10.54(3.57-31.11)$ & $7.47(1.73-32.34)$ \\
\hline
\end{tabular}

*A minimally adjusted model with age and sex only

"Adjusted by age, sex, body mass index, haemoglobin, white blood count, lymphocyte count, albumin, CD8+ count, D-dimer, and CRP

19. However, frailty is a process with persistent chronic inflammation, whereas severe cases of COVID-19 are characterized by an inflammatory storm. Therefore, the immunologic and inflammatory mechanisms involved in the course of severe COVID-19 cases, which might be different from those involved in frailty, deserve further study. Besides, inflamm-ageing suggests a failure of the cell clearance mechanisms which could aid in the resolution of inflammation after tissue injury or/and pathogen infiltration by indirectly affecting important metabolic signalling pathways [43], which could result in the development and progression of ARDS in COVID19 [44]. We also found that the CD8+ counts in frail COVID-19 patients were significantly lower than that in non-frail COVID-19 patients. This is consistent with the report by Liu et al., showing that the counts of lymphocyte subset (CD4+ and CD8+ T cell) are proportionally associated with disease severity [45]. Cell-mediated immune responses play an important role in virus clearance. $\mathrm{CD} 4+$ and $\mathrm{CD} 8+\mathrm{T}$ cells are required for virus clearance during primary infection in the mucosal tissues [46]. CD8+ T cells are cytotoxic and can kill virally infected cells. Immunosenescence has been suggested to contribute to frailty and characterized by the progressive decline in both the innate and adaptive immune systems, and vice versa [42]. Viral infections usually lead to abnormal changes in the levels of lymphocyte subsets which further impaired immune system functionality [47, 48]. Therefore, frailty-related decline in immune function may explain the association between ageing and increased risk of adverse outcomes.

Our analyses were restricted to older patients with COVID-19 pneumonia, which may introduce collider bias that would undermine the validity of the observed association between frailty and progression to severe pneumonia. Selecting a sample of older patients with COVID-19 pneumonia could induce collider bias in the estimated effect of frailty on progression to severe pneumonia in the absence of adequate control for the unmeasured confounders [49]. We adjusted for several confounders including health characteristics that were associated with progression to severe pneumonia to minimize this bias. Also, simulation studies consistently showed the collider bias to only to have minimal impact on the exposure-outcome association unless the associations between some unmeasured confounders and infection of COVID-19 pneumonia were extremely large [50, 51]. Moreover, collider bias is generally thought to lead to unexpected associations, such as the paradoxical relationship between higher body mass index and better outcomes among heart failure patients [52]. We found that frail patients were more likely to experience severe disease than the non-frail; these results were consistent with the associations between frailty and poor prognostic outcomes among other populations. Therefore, the influence of collider bias on the estimate of the exposureoutcome association in the present study is not likely to be large.

Strengths of our study include that we focus on the population with COVID-19 over 60 years of age-a population that carries a disproportionally high disease burden than younger populations. Our results showed that frailty might be a risk factor for the development of severe disease in older COVID-19 patients. The FRAIL scale can be easily performed in a busy clinic setting and it will not increase the risk of the exposure of the healthcare provider to severe infectious diseases.

Our study has some limitations. First, this study was conducted at a single-centre hospital with limited sample size. A larger, multicentre cohort study of older patients with COVID-19 pneumonia would help further identify the association between frailty and prognosis. Second, all clinical and laboratory characteristics were measured once on admission. It is, therefore, challenging to distinguish confounders from mediators, which may lead to over-adjustment. Future research with repeated measures could advance our understanding about mechanisms underlying the association between frailty and poor prognosis among older COVID-19 patients. Third, the association between frailty and death was not examined in the present study. There were only eight deaths in our sample, making it difficult to study death as an outcome in a rigorous manner. Because deaths met the diagnostic criteria for then severe illness of COVID-19 and we considered death cases as "severe illness" in analyses. In the future, studies with larger sample sizes may help elucidate the relationship between frailty and mortality among COVID-19 patients. Lastly, we did not collect data on treatment options because treatment varied widely from patient to patient due to comorbidities except for antiviral regimen.

\section{Conclusions}

Our study found that the frailty would increase the risk of development of severe disease among older COVID19 patients - a population that carries a disproportionally high disease burden (e.g. ICU admission rate and casefatality rate). Our findings suggested that frailty might be 
a predictor of poor prognosis in older COVID-19 patients. Large multicentre studies are needed to confirm our findings.

\section{Supplementary information}

Supplementary information accompanies this paper at https://doi.org/10. 1186/s12916-020-01761-0.

Additional file 1: Table A1. Univariate analysis for the severe disease.

\section{Abbreviations}

ARDS: Acute respiratory distress syndrome; CCl: Charlson Comorbidity Index; COVID-19: Coronavirus disease 2019; CRP: C-reactive protein; ICU: Intensive care unit; TNF-a: Tumour necrosis factor-a; WHO: World Health Organization

\section{Acknowledgements}

We acknowledge all healthcare workers involved in the diagnosis and treatment of patients in Renmin Hospital of Wuhan University and COVID-19 Medical Team (Hubei) of West China Hospital, Sichuan University.

\section{Authors' contributions}

Dr. Jirong Yue and Dr. Yan Kang had full access to all the data in the study and take responsibility for the integrity of the data and the accuracy of the data analysis. Study concept and design: Yao Ma, Jirong Yue, Yan Kang. Acquisition, analysis, or interpretation of data: Yao Ma, Lisha Hou, Xiufang Yang, Xue Yang, Na Zhao, Zhixin Huang, Jirong Yue, Yan Kang, Chenkai Wu, Yixin Shi. Drafting of the manuscript: Yao Ma. Critical revision of the manuscript for important intellectual content: Yao Ma, Jirong Yue, Chenkai Wu. Statistical analysis: Lisha Hou. Obtained funding: Jirong Yue, Yan Kang. Administrative, technical, or material support: Jirong Yue, Yan Kang, Chenkai Wu. Study supervision: Jirong Yue. The authors read and approved the final manuscript.

\section{Funding}

This study was supported by grants from Chinese National Science \& Technology Pillar Program (2020YFC200066), Sichuan Science and Technology Program (2020YFS0148), 1.3.5 project for disciplines of excellence-Clinical Research Incubation Project, West China Hospital, Sichuan University (19HXFH012), National Clinical Research Center for Geriatrics, West China Hospital, Sichuan University (Z20191003), and Project of Novel Coronavirus Pneumonia in West China Hospital (HX2019nCoV027).

\section{Availability of data and materials}

The datasets used and/or analysed during the current study are available from the corresponding author on reasonable request. Dr. Jirong Yue and Dr. Yan Kang had full access to all the data in the study and take responsibility for the integrity of the data and the accuracy of the data analysis.

\section{Ethics approval and consent to participate}

This study was approved by the Ethics Committee of West China Hospital (West China Hospital \#2020198). Informed verbal consent was obtained from all participants. The requirement for written consent was waived by the Ethics Commission.

\section{Consent for publication}

Not applicable.

\section{Competing interests}

The authors declare that they have no competing interests.

\section{Author details}

'Department of Geriatrics and National Clinical Research Center for Geriatrics, West China Hospital, Sichuan University, Chengdu, Sichuan Province, China. ${ }^{2}$ COVID-19 Medical Assistance Teams (Hubei) of West China Hospital, Sichuan University, Chengdu, Sichuan Province, China. ${ }^{3}$ Mental Health Centre, West China Hospital, Sichuan University, Chengdu, Sichuan Province, China. ${ }^{4}$ Department of Obstetrics and Gynecology, Renmin Hospital of Wuhan University, Wuhan, Hubei Province, China. ${ }^{5}$ Department of
Otolaryngology-Head and Neck Surgery, Renmin Hospital of Wuhan University, Wuhan, Hubei Province, China. ${ }^{6}$ Department of Critical Care Medicine, West China Hospital, Sichuan University, Chengdu, Sichuan Province, China. ${ }^{7}$ State Key Laboratory of Oral Diseases \& National Clinical Research Center for Oral Diseases \& West China School of Stomatology, Sichuan University, Chengdu, Sichuan Province, China. ${ }^{8}$ Global Health Research Center Duke Kunshan University, Suzhou, Jiangsu Province, China.

Received: 15 May 2020 Accepted: 24 August 2020

Published online: 07 September 2020

\section{References}

1. World Health Organization. Coronavirus disease 2019 (COVD-19): situation report-1. January 20, 2020. Accessed 21 Jan 2020. https:/www.who.int/docs/default-source/ coronaviruse/situation-reports/20200121-sitrep-1-2019 ncov.pdf?sfvrsn=20a99c10_4.

2. Huang C, Wang Y, Li X, Ren L, Zhao J, Hu Y, et al. Clinical features of patients infected with 2019 novel coronavirus in Wuhan, China. Lancet. 2020;395(10223):497-506.

3. World Health Organization. Coronavirus disease 2019 (COVID-19): situation report-22. February 10, 2020. Accessed 11 Feb 2020. https://www.who.int/ docs/default-source/coronaviruse/situation-reports/20200211-sitrep-22-ncov. pdf?sfvrsn=fb6d49b1 2 .

4. World Health Organization. Coronavirus disease 2019 (COVID-19): situation report-51. March 11, 2020. Accessed 12 Mar 2020. https://www.who.int/ docs/default-source/coronaviruse/situation-reports/20200311-sitrep-51covid-19.pdf?sfvrsn=1 ba62e57_10.

5. World Health Organization. Coronavirus disease 2019 (COVID-19): situation report-113. May 12, 2020. Accessed 13 May 2020. https:/www.who.int/ docs/default-source/coronaviruse/situation-reports/20200512-covid-19sitrep-113.pdf?sfvrsn=feac3b6d 2.

6. Wu C, Chen X, Cai Y, Xia J, Zhou X, Xu S, et al. Risk factors associated with acute respiratory distress syndrome and death in patients with coronavirus disease 2019 pneumonia in Wuhan, China. JAMA Intern Med. 2020. https:// doi.org/10.1001/jamainternmed.2020.0994.

7. Zhou F, Yu T, Du R, Fan G, Liu Y, Liu Z, et al. Clinical course and risk factors for mortality of adult inpatients with COVID-19 in Wuhan, China: a retrospective cohort study. Lancet. 2020;395(10229):1054-62.

8. Wynants L, Van Calster B, Bonten MMJ, Collins GS, Debray TPA, De Vos M, et al. Prediction models for diagnosis and prognosis of covid-19 infection: systematic review and critical appraisal. BMJ. 2020;7:369:m1328. https://doi. org/10.1136/bmj.m1328.

9. Epidemiology Working Group for NCIP Epidemic Response, Chinese Center for Diseas Control and Prevention. The epidemiological characteristics of an outbreak of 2019 novel coronavirus diseases (COVID-19) in China (in chinese). Chin J of Epidemiol 2020;41(2): 145-151.

10. Centers for Disease Control and Prevention. Severe outcomes among patients with coronavirus disease 2019 (COVID-19) - United States, February 12-March 16, 2020. https:/www.cdc.gov/mmwr/volumes/69/wr/mm6912e2. htm?s_cid=mm6912e2_w.

11. Hans Henri P. Kluge. Statement - Older people are at highest risk from COVID-19, but all must act to prevent community spread. http://www.euro. who.int/en/health-topics/health-emergencies/coronavirus-covid-19/ statements/statement-older-people-are-at-highest-risk-from-covid-19,-but-allmust-act-to-prevent-community-spread.

12. Giwa AL, Desai A, Duca A. Novel 2019 coronavirus SARS-CoV-2 (COVID-19): an overview for emergency clinicians. Emerg Med Pract. 2020;17(5):1-28.

13. Mannelli C. Whose life to save? Scarce resources allocation in the COVID-19 outbreak. J Med Ethics. 2020:1473-4257.

14. Lintern S. "We are making difficult choices": Italian doctor tells of struggle against coronavirus. Independent; March 13, 2020.

15. Nations U. Policy brief: the impact of COVID-19 on older persons. 2020. https://www.un.org/sites/un2.un.org/files/un_policy_brief_on_covid-19_ and_older_persons_1_may_2020.pdf.

16. Geriatric Medicine Branch of Chinese Medical Association. Chinese experts consensus on assessment and intervention for elderly patients with frailty (in chinese). Chin J of Geriatr. 2020;36(3):251-6.

17. Morley JE, Vellas B, van Kan GA, Anker SD, Bauer JM, Bernabei R, et al. Frailty consensus: a call to action. J Am Med Dir Assoc. 2013;14(6):392-7.

18. Collard RM, Boter H, Schoevers RA, Oude Voshaar RC. Prevalence of frailty in community-dwelling older persons: a systematic review. J Am Geriatr Soc. 2012;60(8):1487-92. 
19. Buta BJ, Walston JD, Godino JG, Park M, Kalyani RR, Xue QL, et al. Frailty assessment instruments: systematic characterization of the uses and contexts of highly-cited instruments. Ageing Res Rev. 2016;26:53-61.

20. World Health Organization. Clinical management of severe acute respiratory infection when novel coronavirus ( $\mathrm{nCoV}$ ) infection is suspected: interim guidance. January 28, 2020. Accessed 5 Mar 2020. https://www.who.int/ publications-detail/clinical-management-of-severeacute-respiratory-infectionwhen-novelcoronavirus-(ncov)-infection-is-suspected.

21. Charlson M, Szatrowski TP, Peterson J, Gold J. Validation of a combined comorbidity index. J Clin Epidemiol. 1994;47(11):1245-51.

22. Morley JE, Malmstrom TK, Miller DK. A simple frailty questionnaire (FRAIL) predicts outcomes in middle aged African Americans. J Nutr Health Aging. 2012 Jul;16(7):601-8

23. Definition Task Force ARDS, Ranieri VM, Rubenfeld GD, et al. Acute respiratory distress syndrome: the Berlin Definition. JAMA. 2012;307:2526-33.

24. Wang L, He W, Yu X, Hu D, Bao M, Liu H, et al. Coronavirus disease 2019 in elderly patients: Characteristics and prognostic factors based on 4-week follow-up. J Infect. 2020;80(6):639-45.

25. O'Caoimh R, Galluzzo L, Rodríguez-Laso Á, Van der Heyden J, Ranhoff AH, Lamprini-Koula M, et al. Prevalence of frailty at population level in European ADVANTAGE Joint Action Member States: a systematic review and metaanalysis. Ann Ist Super Sanita. 2018;54(3):226-38.

26. Finnerty BM, Gray KD, Ullmann TM, Zarnegar R, Fahey TJ 3rd, Beninato T. Frailty is more predictive than age for complications after thyroidectomy for multinodular goiter. World J Surg. 2020;44(6):1876-84.

27. McChesney SL, Canter DJ, Monlezun DJ, Green H, Margolin DA. Modified frailty index predicts postoperative outcomes in patients undergoing radical pelvic surgery. Am Surg. 2020;86(2):95-103.

28. Dent E, Morley JE, Cruz-Jentoft AJ, Woodhouse L, Rodríguez-Mañas L, Fried LP, et al. Physical frailty: ICFSR International Clinical Practice Guidelines for identification and management. J Nutr Health Aging. 2019;23(9):771-87.

29. Aprahamian I, Aricó de Almeida GV, de Vasconcellos Romanin CF, Gomes Caldas T, Antunes Yoshitake NT, Bataglini L, et al. Frailty could predict death in older adults after admission to emergency department? A 6-month prospective study from a middle-income country. J Nutr Health Aging. 2019;23:641-7

30. Woo J, Yang X, Tin Lui L, Li Q, Fai Cheng K, Fan Y, et al. Utility of the FRAlL questionnaire in detecting heart failure with preserved ejection fraction. J Nutr Health Aging. 2019;23(4):373-7.

31. De Silva TR, Theou O, Vellas B, Cesari M4 Visvanathan R. Frailty screening (FRAlL-NH) and mortality in French nursing homes: results from the incidence of pneumonia and related consequences in nursing home residents study. J Am Med Dir Assoc 2018; 19(5):411-414.

32. Bagshaw SM, Stelfox HT, McDermid RC, Rolfson DB, Tsuyuki RT, Baig N, et al. Association between frailty and short- and long-term outcomes among critically ill patients: a multicentre prospective cohort study. CMAJ. 2014; 186(2):E95-102.

33. Bagshaw SM, Stelfox HT, Johnson JA, McDermid RC, Rolfson DB, Tsuyuki RT, et al. Long-term association between frailty and health-related quality of life among survivors of critical illness: a prospective multicenter cohort study. Crit Care Med. 2015;43(5):973-82.

34. Kundi H, Wadhera RK, Strom JB, Valsdottir LR, Shen C, Kazi DS, et al. Association of frailty with 30-day outcomes for acute myocardial infarction, heart failure, and pneumonia among elderly adults. JAMA Cardiol. 2019 Sep 25. https://doi.org/10.1001/jamacardio.2019.3511.

35. Singer JP, Lederer DJ, Baldwin MR. Frailty in pulmonary and critical care medicine. Ann Am Thorac Soc. 2016;13(8):1394-404.

36. Rockwood K, Mitnitski A. Frailty in relation to the accumulation of deficits. J Gerontol A Biol Sci Med Sci. 2007;62(7):722-7.

37. Gill TM, Gahbauer EA, Allore HG, Han L. Transitions between frailty states among community-living older persons. Arch Intern Med. 2006;166(4):418-23.

38. Lang PO, Michel JP, Zekry D. Frailty syndrome: a transitional state in a dynamic process. Gerontology. 2009;55(5):539-49.

39. Theou O, Brothers TD, Rockwood MR, Haardt D, Mitnitski A, Rockwood K. Exploring the relationship between national economic indicators and relative fitness and frailty in middle-aged and older Europeans. Age Ageing. 2013;42(5):614-9.

40. Soysal P, Arik F, Smith L, Jackson SE, Isik AT. Inflammation, frailty and cardiovascular disease. Adv Exp Med Biol. 2020;1216:55-64.
41. Soysal P, Stubbs B, Lucato P, Luchini C, Solmi M, Peluso R, et al. Inflammation and frailty in the elderly: a systematic review and metaanalysis. Ageing Res Rev. 2016;31:1-8.

42. Haq K, McElhaney JE. Ageing and respiratory infections: the airway of ageing. Immunol Lett. 2014;162(1 Pt B):323-8.

43. Sendama $W$. The effect of ageing on the resolution of inflammation. Ageing Res Rev. 2020;57:101000

44. Ye Q, Wang B, Mao J. The pathogenesis and treatment of the 'Cytokine Storm' in COVID-19. J Infect. 2020;75(7):1564-81.

45. Liu Z, Long W, Tu M, Chen S, Huang Y, Wang S, et al. Lymphocyte subset $(C D 4+, C D 8+)$ counts reflect the severity of infection and predict the clinical outcomes in patients with COVID-19. J Infect. 2020;81(2):318-56.

46. Kohlmeier J, Woodland D. Immunity to respiratory viruses. Annu Rev Immunol. 2009;27:61-82.

47. Van Dam JG, Damoiseaux J, Christiaans MHL, Bruggeman CA. Acute primary infection with cytomegalovirus (CMV) in kidney transplant recipients results in the appearance of a phenotypically aberrant CD8(+) T cell population. Microbiol Immunol. 2000;44(12):1011-7.

48. Veazey R, Ling BH, Pandrea I, McClure H, Lackner A, Marx P. Decreased CCR5 expression on CD4(+) T cells of SIV-infected sooty Mangabeys. AIDS Res Hum Retrovir. 2003;19(3):227-33.

49. Greenland S, Pearl J, Robins JM. Causal diagrams for epidemiologic research. Epidemiology. 1999;10:37-48.

50. Liu W, Brookhart MA, Schneeweiss S, Mi X, Setoguchi S. Implications of M bias in epidemiologic studies: a simulation study. Am J Epidemiol. 2012; 176(10):938-48.

51. Pizzi C, De Stavola B, Merletti F, Bellocco R, dos Santos Silva I, Pearce N, et al. Sample selection and validity of exposure-disease association estimates in cohort studies. J Epidemiol Community Health. 2011;65(5):407-11.

52. Curtis JP, Selter JG, Wang Y, Rathore SS, Jovin IS, Jadbabaie F, et al. The obesity paradox: body mass index and outcomes in patients with heart failure. Arch Intern Med. 2005;165:55-61.

\section{Publisher's Note}

Springer Nature remains neutral with regard to jurisdictional claims in published maps and institutional affiliations.

Ready to submit your research? Choose BMC and benefit from

- fast, convenient online submission

- thorough peer review by experienced researchers in your field

- rapid publication on acceptance

- support for research data, including large and complex data types

- gold Open Access which fosters wider collaboration and increased citations

- maximum visibility for your research: over $100 \mathrm{M}$ website views per year

At $\mathrm{BMC}$, research is always in progress.

Learn more biomedcentral.com/submissions 